\title{
Por uma relatãão entre inteligência da fé e racionalidade cientifica no contexto atual
}

\author{
For a connection between intelligence of the faith and scientific \\ rationality in the present context
}

Recebido: 23/11/2016. Aprovado: 23/02/2017.

\section{Tiago de Fraga Gomes*}

Resumo: A pretensão de onisciência científica é uma ideologia moderna, a qual quis exorcizar a fé e a religião da sociedade. A modernidade prognosticou não precisar mais da religião para manter a ordem social, pois, para isso, bastaria uma racionalidade. $O$ movimento raciocêntrico cartesiano e posteriormente, todo iluminismo francês, vão lançar as bases de uma subjetividade autônoma que não necessita de nenhuma legitimação exterior ou mesmo sacra. O cientificismo impede a ciência de cumprir a sua vocação na expansão do conhecimento; impõe limites à consideração da verdade; deturpa a amplitude e a profundidade da inclinação natural inerente ao desejo de conhecer; opera uma obtusidade nefasta no horizonte do conhecimento, encurtando e limitando as suas perspectivas. Diante de um universo em evolução, a fé revelada ajuda a ciência a conviver com a incompletude e a ambiguidade, e a desenvolver as suas pesquisas com uma visão esperançosa da realidade. Conciliar a inteligência da fé com a racionalidade científica significa deslocar a perspectiva da metafísica do passado para o futuro escatológico, do pessimismo materialista para a esperança transformadora, da compreensão limitada para a abertura a uma plena inteligibilidade, ampliando as possibilidades do desejo de conhecer.

Palavras-chave: Fé. Religião. Teologia. Razão. Ciência. Cientificismo.

\begin{abstract}
The claim to scientific omniscience is a modern ideology, which seeks to exorcise the faith and the religion from the society. Modernity foretold religion was no longer needed to maintain social order, for a rationality would suffice. The Cartesian raciocentric movement and later all French Enlightenment would lay the foundations of an autonomous subjectivity that needs no external nor sacral legitimation. Scientism prevents science from fulfilling its vocation in the expansion of knowledge; it imposes limits on the consideration of truth; it distorts the breadth and the depth of the natural inclination inherent in the desire to know; it operates a nefarious obtuseness on the horizon of knowledge, shortening and limiting its perspectives. Faced with an evolving universe, revealed faith helps science to cope with incompleteness and ambiguity, and to develop its research with a hopeful view of reality. To conciliate the intelligence of faith with scientific rationality means to shift the perspective from the metaphysics of the past to the eschatological future, from materialist pessimism to transforming hope, from limited understanding to openness for full intelligibility, expanding the possibilities of the desire to know.
\end{abstract}

Keywords: Faith. Religion. Theology. Reason. Science. Scientism.

* Doutorando em Teologia pela PUCRS, bolsista da CAPES. Mestre em Teologia pela PUCRS (2015). Bacharel em Teologia pela PUCRS (2012). Bacharel em Filosofia pela PUCRS (2007). Presbítero da Diocese de Osório.

E-mail: tiago_mail@yahoo.com.br 


\section{Introdução}

Quando se fala em teologia e ciência, muitos questionamentos vêm à tona. Moltmann, por exemplo, se pergunta: "Que sentido pode ter a teologia cristã num mundo que se tornou, e se tornará cada vez mais, o mundo do homem?" Essa questão remete à própria razão de ser da teologia, e se constitui numa indagação radical ao seu estatuto epistemológico. ${ }^{2}$ Em outras palavras, essa questão pode ser transcrita da seguinte maneira: Como trabalhar a inteligência da fé em um contexto extremamente secularizado e dominado pela racionalidade científica e instrumental? Nos últimos séculos, o critério de cientificidade regeu-se pelo paradigma da verificação experimental, da matematização ${ }^{3}$ e do pragmatismo instrumental. A teologia enquanto inteligência da fé e ciência hermenêutica da revelação de Deus na história, mais do que nunca, precisa justificar seu status científico diante de uma mentalidade empírico-experimental. Mesmo que a teologia assuma o limite de ser "um discurso sobre uma linguagem que fala humanamente de Deus" ${ }^{4}$, e mesmo que reconheça que a economia da revelação não pode ser objeto de experimentações com vistas a comprovações laboratoriais, porém, precisa provar que não está em contradição com a racionalidade científica, mas antes, tem seu próprio estatuto epistemológico. No fundo, a convivência entre ciência e fé tem sido turbulenta devido a uma falta de conhecimento técnico recíproco.

O que acontece, é que muitas vezes o cientista não conhece as Escrituras e a mensagem teológica da religião, e o teólogo permanece

1 MOLTMANN, Jürgen. Ciência e sabedoria, p. 15.

2 Atualmente, é consenso que a racionalidade teológica orienta-se no interior de uma experiência de fé, no âmbito da tradição comunitária. O verdadeiro teólogo é místico e mistagogo, pois ao mesmo tempo em que fala do mistério experimentado aos seus interlocutores, os conduz à experiência do mistério. Mas o teólogo possui também uma vocação crítica e profética, que faz pensar, e conduz a fé à sua inteligência. $\mathrm{O}$ teólogo busca expor as razões da fé, cuja finalidade no fundo é pastoral, comunitária e humanitária. (Cf. SUSIN, Luiz Carlos. O estatuto epistemológico da teologia como ciência da fé e a sua responsabilidade pública no âmbito das ciências e da sociedade pluralista, p. 557). Sendo assim, a teologia trabalha com duas comunidades: a de fé e a científica.

3 O termo "matematização" corresponde à redução à forma matemática, e significa basicamente "sistematizar", "esquematizar", nos moldes da ciência matemática, a qual voltou a florescer fortemente nos primórdios da modernidade.

4 GEFFRÉ, Claude. Crer e interpretar, p. 33. 
ignorante quanto às conquistas realizadas pela ciência. Além disso, para permanecer imparcial em seus posicionamentos, o cientista acaba optando por uma postura não só agnóstica, mas também ateia. Esse ceticismo acaba por constranger o teólogo e a comunidade de fé. ${ }^{5}$ Porém, muitos teólogos, preferem acolher os avanços da ciência, pois partem da premissa de que toda verdade não pode estar em contraposição com a verdade de Deus. Por isso, tentam acomodar os resultados das pesquisas científicas aos dados da fé. ${ }^{6}$ Toda redução unilateral, seja das ciências à teologia, como aconteceu no medievo confessionalmente homogêneo e teocêntrico, quanto da teologia às ciências, como o ocorrido na sociedade iluminista e positivista ${ }^{7}$, consiste numa redução que desconsidera as identidades e os enfoques em sua especificidade. A presente pesquisa pretende trabalhar por uma aproximação das relações entre inteligência da fé e racionalidade científica sob os seguintes aspectos: respeito mútuo à condição dos estatutos epistemológicos específicos e superação de antigos preconceitos e ideologias unilaterais.

\section{Por uma relação de respeito aos estatutos epistemológicos}

A ciência está cada vez mais se desenvolvendo e ampliando as suas pesquisas. "As descobertas científicas elucidam cada vez mais o universo e favorecem o amadurecimento da fé e do próprio conhecimento." ${ }^{\circledR}$ ão há dúvida de que "a pesquisa continuada nas ciências conduziu ao progresso de nosso conhecimento." A religião não se coloca contra a ciência, porém, não se limita aos seus moldes. Ciência e religião podem colaborar uma com a outra. A religião, por exemplo, pode ajudar a ciência a buscar a sabedoria, pois nem tudo o que é tecnicamente possível, é eticamente praticável. É preciso discernimento e empenho do conhecimento em favor da vida. "Nem todo saber serve à vida, nem todo conhecimento nos torna sábios. É pelas experiências, positivas e negativas, que fica-

5 Cf. CALDANA, Marcelo. Deus, o esquecido da ciência, p. 181-182.

6 Cf. McGRATH, Alister E. Fundamentos do diálogo entre ciência e religião, p. 67.

7 Cf. SUSIN, Luiz Carlos. O estatuto epistemológico da teologia como ciência da fé e a sua responsabilidade pública no âmbito das ciências e da sociedade pluralista, p. 556.

8 BARTH, Wilmar Luiz. Religião, ciência e bioética, p. 19.

9 ZILLES, Urbano. A crítica da religião, p. 13. 
mos sábios." ${ }^{10} \mathrm{O}$ domínio humano unilateral e instrumental emudece a natureza e esvazia o ser humano.

É necessário esclarecer que "ninguém, a rigor, crê ou deixa de crer em Deus por causa da ciência. De maneira análoga, ninguém deixa de ser cientista por causa da fé ou descrença." ${ }^{11}$ Enquanto o cientista trabalha no nível específico da racionalidade experimental, o crente está envolvido em uma dinâmica mais profunda e globalizante, que envolve as dimensões da racionalidade reflexiva, das crenças e das emoções. Pascal já dizia que "o coração tem suas razões que a razão não conhece." 12 No entanto, o racionalismo ocidental moderno, reduziu o ser humano à dimensão da razão. No Discurso do método, Descartes cunhou a expressão lapidar "cogito, ergo sum" como a evidência primeira e a mais clara das verdades, protagonizando uma mudança paradigmática. Nas Meditações, Descartes afirma: "O pensamento é um atributo que me pertence; só ele não pode ser separado de mim. Eu sou, eu existo." ${ }^{13} \mathrm{Na}$ filosofia de Descartes "o cogito se constitui no modelo e critério de todas as verdades." ${ }_{14}$ A ciência moderna tem a pretensão cartesiana de reduzir tudo à racionalidade, como se não houvessem outras dimensões constitutivas do ser humano. Com Descartes, o que aconteceu não foi propriamente uma virada antropocêntrica, mas sim, uma virada raciocêntrica, que supervalorizou a razão.

Diante da prepotência racionalista e cientificista, é preciso lembrar que "é da própria natureza da revelação situar-se além do escopo da certificação científica." ${ }^{15}$ A transcendência excede o campo da ciência. O Deus da fé revelada ${ }^{16}$ não pode ser objeto de controle experimental, nem pode ser submetido à dominação científica. "As

10 MOLTMANN, Jürgen. Ciência e sabedoria, p. 44.

11 ZILLES, Urbano. Crer e compreender, p. 153.

12 PASCAL, Blaise. Pensamentos, p. 107.

13 DESCARTES, René. Meditações, p. 128.

14 JESUS, Luciano Marques de. A questão de Deus na filosofia de Descartes, p. 45.

15 HAUGHT, John F. Cristianismo e ciência, p. 249.

16 Segundo Haught, ao menos para os cristãos, a revelação se configura e se sustenta sob a forma de promessa. Nesse sentido, "só se e quando uma promessa se cumpre pode nossa confiança nela ser plenamente justificada." (HAUGHT, John F. Cristianismo e ciência, p. 250). No fundo, a justificação da verdade revelada tem um caráter escatológico, está sempre entre o "já" dos sinais da manifestação histórica que a credibilizam para a fé, e o "ainda-não" que aguarda a confirmação futura da esperança de sua realização plena. 
ciências modernas não provam nem negam a transcendência do homem nem a existência de Deus." ${ }^{17}$ As pesquisas científicas se enquadram nos parâmetros da delimitação e da parcialidade, não tocam o Absoluto Totalmente Outro, nem mesmo solucionam as questões globais ou do sentido da vida. "Para os indivíduos que se pautam pela ciência e por seu método experimental, a questão da verdade importa bem mais que a do sentido."18 Por isso mesmo, "quem hoje crê em Deus deve lutar por fraternidade, justiça e progresso na ciência, sem limitar-se ao conhecimento científico. A fé, todavia, não se reduz a um simples problema da razão." ${ }^{19}$ A fé e a ciência são duas grandezas que operam na história da humanidade. Porém, desde o Renascimento e a subsequente revolução científica, o equilíbrio entre essas duas forças foi afetado, estabelecendo-se um conflito violento, ao invés de uma complementaridade integral. ${ }^{20}$ Atualmente, o senso comum tem uma imagem bastante simplista e caricatural a respeito da ciência, como se os descobrimentos científicos fossem o produto de procedimentos teóricos claros e inequívocos, resultando desse processo uma verdade científica inquestionável. Porém, a realidade é mais complexa e interessante do que isso. ${ }^{21}$

Entre fé e razão não há contradição, mas complementaridade. "Não há verdades duplas, isto é, contraditórias; a ciência autêntica, refletida, prudente, consciente de seus limites e de sua parte de hi-

$17 \quad$ ZILLES, Urbano. Desafios atuais para a teologia, p. 41.

18 HAUGHT, John F. Cristianismo e ciência, p. 247. Sobre a questão da verdade, a ciência moderna adota a concepção tradicional da correspondência entre a mente (teoria) e o objeto (realidade). Porém, em um sentido mais abrangente, pode ser definida como a "busca pelo próprio desejo de conhecer" (HAUGHT, John F. Cristianismo e ciência, p. 251), que envolve quatro atos cognitivos: experiência, entendimento, julgamento e decisão. Ser amante da verdade significa ser fiel a essa busca gnosiológica. Além do mais, a verdade não pode ser possuída, como o querem os naturalistas científicos, que tentam "contê-la e encapsulá-la pelo método científico." (HAUGHT, John F. Cristianismo e ciência, p. 254). É preciso deixar-se possuir pela verdade. "Só depois de submeter-se aos postulados da revelação, tornando-se ao mesmo tempo plenamente consciente do próprio desejo de conhecer, é que se está em condições de avaliar o status de verdade da própria fé." (HAUGHT, John F. Cristianismo e ciência, p. 255). Não há como definir de uma forma cientificamente neutra o status de verdade da revelação, pois, como afirma Tillich, logo na primeira página de sua obra Dynamics of Faith, a fé é uma questão de interesse último.

ZILLES, Urbano. O problema do conhecimento de Deus, p. 86. 
póteses, não contradiz a fé." ${ }^{22}$ Como afirma o Papa João Paulo II na Fides et Ratio, "a fé e a razão constituem como que as duas asas pelas quais o espírito humano se eleva à contemplação da verdade.” (FR 1). Segundo Haught, a fé precisa "abrir-se aos resultados da investigação científica." ${ }^{23}$ No entanto, é preciso clarear os campos de atuação de cada uma dessas dimensões, para que não haja confusão, pois, como diz Rahner, "verdade de Deus e imagem do mundo são duas coisas diferentes. Hoje compreendemos que não podemos talhar uma imagem de Deus com o material deste mundo. ${ }^{24}$ Cada instância precisa ser considerada e respeitada nas dimensões em que atua. Enquanto que a fé diz respeito ao âmbito da transcendência, a razão e a ciência situam-se no campo da imanência. Não é possível estender a ciência à transcendência, nem reduzir a fé à imanência. As duas sairiam descaracterizadas. Porém, há a possibilidade de diálogo entre ambas, e como todo bom diálogo, é fundamental que se respeite a alteridade irredutível dos interlocutores.

Sobre o conceito de verdade no âmbito da religião, pode-se falar em um sentido múltiplo e diverso, sem propriamente aceder a um universal totalizante, mas a uma quantidade de diferentes significados ${ }^{25}$, relativamente às experiências dos sujeitos que crêem. Isso porque "a fé é dom de Deus, mas, inserida na finitude humana, pode estar marcada pelas imperfeições que são nossas. É a luz divina imersa na obscuridade do homem. ${ }^{.26}$ A fé é um dom divino que se realiza na pluralidade das experiências humanas e se encarna nas culturas. A experiência do mistério ganha muitas faces culturais. No entanto, crer exige correspondência, significa assumir um comportamento diante de um mistério, "é adotar uma atitude, endereçar-se por uma caminho"27; é aderir e depositar a confiança no divino revelado. "A razão técnico-científica não é capaz de explicar por que o ser humano é um ser inquieto, que busca, que pergunta, que deseja, sempre, libertar-se sem nunca parar, o que só se entende pelo fato de a razão não se limitar à esfera da manipulação dos fenômenos. ${ }^{28}$ A racionalidade humana não está fadada à fatalidade das

\footnotetext{
22 RAHNER, Karl. Teologia e ciência, p. 13.

23 HAUGHT, John F. Cristianismo e ciência, p. 248.

24 RAHNER, Karl. Teologia e ciência, p. 20.

25 Cf. SEIFERT, Josef. Pessoa, crença religiosa e verdade, p. 137.

26 FREIRE-MAIA, Newton. Criação e evolução, p. 85.

27 GESCHÉ, Adolphe. O ser humano, p. 33.

28 OLIVEIRA, Manfredo Araújo de. Diálogos entre razão e fé, p. 31.
} 
leis da física, mas poderia ser compreendida em última instância como abertura dinâmica ao mundo, aos seres e ao Ser Totalmente Outro, Mistério Absoluto, tremendo e fascinante.

Há milênios que o ser humano se coloca diante dos mistérios do mundo e da vida com admiração e espanto, e "sempre que a natureza essencial das coisas passa pelo crivo analítico do intelecto, deve efetivamente afigurar-se absurda ou paradoxal. Tal fato sempre foi reconhecido pelos místicos; para a ciência, entretanto, só veio a se tornar um problema muito recentemente." ${ }^{29}$ A pretensão de uma razão totalizadora da verdade é algo moderno. "O pensamento moderno caracteriza-se por categorias racionalistas, críticas e, sobretudo, analíticas. Pesquisas históricas ensinam-nos que nem sempre foi assim, que a razão humana não é a única dimensão do homem e os conceitos não expressam a totalidade imutável da verdade. ${ }^{30}$ É uma questão de sinceridade histórica e de humildade intelectual reconhecer que não temos todas as respostas para todos os fenômenos observáveis, e que há muitos mistérios que ultrapassam a competência da racionalidade científica atual. A pretensão de onisciência científica é uma ideologia moderna, a qual quis exorcizar a fé e a religião da sociedade.

\section{Por uma relação de superação de antigos preconceitos}

A modernidade prognosticou não precisar mais da religião para manter a ordem social, pois, para isso, bastaria uma racionalidade. $\mathrm{O}$ movimento raciocêntrico cartesiano ${ }^{31}$ e posteriormente, todo iluminismo francês, vão lançar as bases de uma subjetividade autônoma que não necessita de nenhuma legitimação exterior ou mesmo sacra. "Os efeitos do Iluminismo francês no plano intelectual foram avassaladores. Daquela época em diante, passou-se a considerar sinônimas as palavras teologia (ou religião) e atraso." ${ }^{32}$ Além do mais, o deslocamento do relógio das

CAPRA, Fritjof. O Tao da física, p. 45.

ZILLES, Urbano. Pierre Teilhard de Chardin, p. 37.

31 Por "movimento raciocêntrico", à semelhança do neologismo "logocentrismo", recorrente na literatura filosófica contemporânea, pode-se compreender a forma de pensar moderna que tem no racionalismo a base para se afirmar um novo paradigma a partir da concepção cartesiana do "penso, logo existo". A razão (ratio, logos) coloca-se no centro, como critério avaliativo e balizador da realidade perscrutada pelo ser humano. 
torres das igrejas e dos mosteiros para as fábricas, conectou o tempo ao dinamismo da economia, retirando-o do olhar da eternidade. De uma economia da salvação passou-se a uma economia da produção. O futuro como projeto social e escatológico tornou-se pessoal, o passado foi lavado pela psicanálise e pela desconstrução, e o presente ansiogênico tornou-se fluidez incerta. $\mathrm{O}$ ato de crer na era secular é mais maduro, pois é opção pessoal. Onde a maioria não tem referencial transcendente, é mais difícil crer. É preciso justificar, dar as razões da fé $(1 P d 3,15)$ em espaço de descrença.

A ciência moderna teve um papel importante na desconstrução do imponente edifício da fé medieval, por intermédio das ideologias naturalista ${ }^{33} \mathrm{e}$ antibiblicista. "O naturalismo científico, caracterizado como é pela lógica indutiva, refuta as pretensões do cristianismo por julgá-las falíveis porque empiricamente insuscetíveis de verificação." ${ }^{34}$ Hoje, se faz necessário que se dissipem antigos mitos e preconceitos, fomentando uma nova visão das relações entre fé e ciência, através de uma aproximação entre ambas. ${ }^{35}$ É preciso entender que todo conhecimento humano está sob o signo da relatividade, e que "nada nos autoriza a substanciar a ciência, entendendo-a como sujeito absoluto, independente de vínculos históricos, sociais e psicológicos. Na realidade, a ciência sempre foi feita por homens de seu tempo." ${ }^{36}$ Toda forma de conhecimento humano é finita e limitada. Toda pretensão de universalidade afunda suas raízes na

33 Os naturalistas científicos insistem de que a verdade revelada, para ser aceita precisa passar pelo crivo e aprovação da verificação. Porém, como afirma Haught, "é da própria natureza da revelação situar-se além do escopo da certificação científica. Inevitavelmente, os naturalistas científicos responderão que essa é uma postura evasiva, e chegarão a reiterar uma vez mais que nada verdadeiramente real pode existir para além do potencial alcance da ciência. Mas uma réplica justificável é que essa pretensão científica dos naturalistas tampouco pode ser cientificamente corroborada. Não é menos uma questão de fé dos que as doutrinas religiosas. A crença de que a ciência é a única via confiável de acesso à verdade certamente foge ao possível escopo da verificação científica." (HAUGHT, John F. Cristianismo e ciência, p. 249). Essa é a razão pela qual a ciência deve respeitar a instância da fé, não a submetendo ao peso de um fardo que ela mesma não pode suportar. A alegação dos naturalistas sobre a irracionalidade do ato de fé pode ser replicada pela constatação de que os próprios pressupostos do naturalismo, de que "a natureza é tudo o que existe", se fundam sob uma aposta de fé que não tem comprovação científica. (Cf. HAUGHT, John F. Cristianismo e ciência, p. 256).

34 HAUGHT, John F. Cristianismo e ciência, p. 247.

35 Cf. NUMBERS, Ronald. Mitos e verdades em ciência e religião, p. 198-199.

36 PAIVA, Geraldo José de. A religião dos cientistas, p. 13. 
delimitação de determinado contexto. Nesse sentido, "o pluralismo teórico veio para ficar. Portanto, ele deverá impregnar doravante a própria epistemologia científica. Colocando-nos em um patamar de coexistência de teorias múltiplas, simultâneas e alternativas sobre o mesmo assunto." ${ }^{37}$ Atualmente, é preciso desistir de hermenêuticas universalistas e unificadoras, para aceitar a coexistência de múltiplas versões da verdade, ou seja, de que não há certezas definitivas no âmbito da provisoriedade.

Há quem diga que sobre fatos não é possível discutir, pois os mesmos "são inquestionáveis em razão de comprovação ou da evidência que possuem." ${ }^{38}$ Realmente, muitos dados parecem ser incontestáveis, pois contra fatos, não há argumentos. A luz que ilumina, o ar que se respira, o frio e o calor, são obviedades cotidianas que não necessitam de crença, apenas de conhecimento. Através da observação e da pesquisa, se aprofunda e se cataloga as constâncias e as regularidades dos fenômenos físicos, e se elaboram parâmetros, sendo firmadas hipóteses. Negar o conhecimento científico não é uma questão de fé, mas de ignorância e fundamentalismo. A ciência se fundamenta sobre o critério da verificabilidade, e não do testemunho ou da autoridade. A verdade científica se impõe pela força imparcial de suas evidências. Porém, é necessário que se façam algumas ressalvas.

Sobre o problema da objetividade científica, por exemplo, ela nunca será absoluta, pois pesa sobre os dados a interpretação dos observadores. "O acesso à realidade sempre acaba mediado pelo método, pelas lentes, pelas antenas de quem contempla e analisa." ${ }^{39}$ Em ciência, ao anseio de uma completa objetividade a respeito do observável, soma-se a ideologia da imparcialidade científica, como se o conhecimento produzido pela ciência fosse completamente neutro de subjetividade, e por isso, completamente confiável e inquestionável. A subjetividade tornou-se um tabu na era moderna. ${ }^{40}$ Esquece-se que a ciência trabalha com probabilidades, hipóteses, especulações e projeções. Não há garantias absolutas. Todo conhecimento científico se baseia em premissas, nem sempre passíveis de comprovação. O conhecimento humano é limitado, “ele não é tão seguro quanto reivindica. É parcial, capta apenas pers-

\footnotetext{
37 ASSMANN, Hugo. Teologia e ciências, p. 95.

38 BRAKEMEIER, Gottfried. Ciência ou religião, p. 27.

39 BRAKEMEIER, Gottfried. Ciência ou religião, p. 28.

40

Cf. HAUGHT, John F. Cristianismo e ciência, p. 259.
} 
pectivas e é cego para determinadas realidades." ${ }^{41}$ Mesmo com essas ressalvas, vivemos sob o império e o monopólio da cientificidade como absolutização da verdade. Por carecer de verificação empírica, tudo que se refere à fé e à religião, carece de credibilidade para a ciência. Há, assim, uma tentativa de imanentização da verdade.

\section{Por uma relação que supere ideologias unilaterais}

A grande questão das relações entre fé revelada e racionalidade científica diz respeito à ideologia ateia cientificista. Segundo Brakemeier, a fé necessita de algo que se revele digno de confiança. "É a confiabilidade de Deus que motiva o ser humano a crer. Eis por que fé em Deus é um dom do próprio Deus. Para despertá-la, importa anunciar as obras de Deus, proclamar suas maravilhas." ${ }^{42}$ Cabe ao ser humano acolher essa mensagem e confiar na graça divina. Confia-se em Deus por que Ele se revela confiável, analogamente ao que acontece em uma amizade. A atitude crente se fundamenta na confiança em Deus. De maneira semelhante, a atitude ateia se baseia em uma relação de confiança com a ciência. Para o ateu, mesmo que a ciência não seja capaz de explicar que determinado fenômeno não seja um milagre, crê e espera que futuramente a ciência seja capaz de fazê-lo. $\mathrm{O}$ ateu "acredita que não há nada além do mundo natural e físico, nenhuma inteligência sobrenatural vagando por trás do universo observável, que não existe uma alma que sobrevive ao corpo e que não existem milagres." ${ }^{43}$ Isso é uma premissa,ou melhor, um postulado ideológico. Tudo aquilo cuja aparência remeta para além de uma explicação plausível ao nível da ciência atual, seria potencialmente mistério passível de ser desvendado pela racionalidade científica.

Quando a ciência e a religião são vistas como inimigas empenhadas em um combate mortal, de ambos os lados desse conflito, há pessoas fomentando uma agressiva unilateralidade, especialmente quando o assunto diz respeito à teoria da evolução. $\mathrm{O}$ estranhamento entre ciência e religião ocorre quando uma invade a competência específica da outra, havendo um desrespeito mútuo. $\mathrm{O}$ que muitas vezes não se leva em considera-

41 BRAKEMEIER, Gottfried. Ciência ou religião, p. 30.

42 BRAKEMEIER, Gottfried. Ciência ou religião, p. 34.

43 DAWKINS, Richard. Deus, um delírio, p. 37. 
ção, é que, enquanto a ciência se ocupa com as relações de causalidade entre os fenômenos observáveis e experimentáveis, a religião tem como meta o sentido e o propósito da vida, em um sentido mais axiológico e existencial. Ambas as perspectivas são necessárias e complementares. Além disso, muitas pessoas hoje percebem que tanto a ciência quanto a religião levantam questões que sozinhas e isoladas não seriam capazes de responder. Questões tais como o sentido da existência e da ordem do universo e da própria vida. Aqueles que são a favor de um diálogo entre ciência e religião têm consciência das limitações de ambos os campos, e por isso, não reivindicam a posse de todas as respostas. ${ }^{44}$ As descobertas científicas podem ajudar numa reformulação de muitas visões da fé a respeito de Deus e da natureza humana, como por exemplo, "a ciência revela que o universo, nosso planeta e mesmo a vida estão comprometidos com um processo evolucionário"45; e a própria religião pode ajudar a ciência a discernir os valores fundamentais envolvidos em muitas de suas pesquisas, especialmente aquelas que dizem respeito à manutenção da vida humana em sua sacralidade.

Em tempos de cientificismo, ao teólogo cabe demonstrar a plena coerência entre a fé cristã e pensamento evolutivo, a partir da premissa de que o devir cósmico é um componente fundamental da teologia da criação. ${ }^{46} \mathrm{O}$ teólogo precisa estar atento para as relações entre ciência, história e revelação. Pode-se tomar como exemplo o esforço empreendido por Teilhard de Chardin. "Suas pesquisas arqueológicas e seus estudos sobre a teoria da evolução o levaram a repensar a fé cristã sob a luz do estágio das ciências naturais de seu tempo." ${ }^{47} \mathrm{~A}$ teologia atual precisa dar passos significativos nesse sentido. "O Concílio Vaticano II representou um passo à frente na aceitação geral da teoria evolutiva, na medida em que integra o diálogo com o mundo moderno e as ciências." ${ }^{\prime 48}$ Mas ainda há muito o que fazer para que se realize uma revisão teológica baseada em uma nova apreensão da realidade pelo campo das ciências. A teologia e a fé precisam superar os antigos ranços que as segregam..$^{49} \mathrm{E}$ assim como a ciência pode ajudar a reli-

\footnotetext{
Cf. BARBOUR, Ian G. Quando a ciência encontra a religião, p. 9-10.

COLLINS, Francis S. A linguagem de Deus, p. 53.

Cf. MORANDINI, Simone. Teologia e física, p. 132-133.

HAMMES, Erico João. Teologia e evolução, p. 214.

HAMMES, Erico João. Teologia e evolução, p. 215.

Cf. HAMMES, Erico João. Teologia e evolução, p. 218.
} 
gião a abrir-se a uma visão renovada do universo, a religião pode ser um importante contributo para a ciência, com seus ensinamentos, para influir sobre o comportamento humano, nutrindo uma vida ética diante das possibilidades, uma ascese perante o poder de transformação, e uma práxis consequente com os valores que realmente importam para a vida humana e do planeta. ${ }^{50}$

A realidade é que a ciência se desenvolveu vertiginosamente nos últimos séculos. Muitas descobertas, especialmente na área da física, revolucionaram a vida humana. Nesse sentido, é possível compreender "que com base nos inegáveis triunfos e êxitos alcançados alguns físicos tenham alimentado a esperança de que um dia seria possível decifrar nosso universo." ${ }^{51}$ Porém, apesar dos grande avanços, e das tentações inerentes aos mesmos, é preciso nunca perder de vista que "nenhum método, por mais seguro que seja, nenhum projeto, por mais adequado, nenhuma teoria, por mais que seja exata, podem ser absolutizados." ${ }^{2}$ A ciência não é onipotente. Semelhante ao ateísmo antropológico de Feuerbach, que quis atribuir todos os atributos divinos ao homem, culminando na crítica de Nietzsche da morte de Deus para a emergência de um super-homem, hoje o que geralmente se prega nos púlpitos laboratoriais da ciência é que a religião e a fé se enquadram nas antigas fábulas pré-modernas, sendo necessário atribuir à deusa ciência, a onisciência no conhecimento da realidade e a onipotência na manipulação das forças cósmicas e vitais. Essas posições são desequilibradas e doentias para uma compreensão integral do universo e da vida.

Em nenhum outro momento da história, os cientistas dispuseram de tantas informações como hoje. Ao mesmo tempo, nunca houve antes tantas opiniões acerca do ser humano e de sua origem que fossem tão incertas, imprecisas e múltiplas como no tempo atual..$^{53}$ Os cientistas de várias áreas do conhecimento encheram seus laboratórios com muitas e variadas informações. Porém, sobre todo conhecimento, pesa uma hipoteca social, e a cada informação adquirida, maiores e mais agudos se tornam os questionamentos. "Outrora a ciência se deliciava deslumbrada com os dados tímidos que chegavam do espaço. Hoje

\footnotetext{
50 Cf. ALLĖGRE, Claude. Deus face à ciência, p. 139-140.

51 KÜNG, Hans. O princípio de todas as coisas, p. 13.

52 KÜNG, Hans. O princípio de todas as coisas, p. 79.

53 Cf. SCHELER, M. La idea del hombre y la historia, p. 9.
} 
ela está como que entorpecida com uma avalanche de informações sem resposta alguma." ${ }^{54}$ Atualmente, tem-se muito conhecimento e pouca sabedoria. A hiper-especialização fez cada área do conhecimento saber cada vez mais sobre cada vez menos. Como afirma Lyotard, com a expulsão das metanarrativas da vida social, representadas em grande parte pelas religiões, houve uma desarticulação das experiências e dos conhecimentos, um afastamento da instância da sabedoria, e uma aproximação do paradigma instrumental e tecnocrático. Hoje o que vale, não é o que torna o ser humano mais sábio, mas o que o torna mais poderoso. "As ciências são percebidas como saber para dominar." ${ }^{55}$ Infelizmente, o que vigora atualmente é o axioma de Bacon, "saber é poder", segundo o qual, o conhecimento é uma forma de domínio.

Apesar de ser um desdobramento legítimo da vontade humana de conhecer, "a redução metodológica característica do método científico pode se tornar refém da vontade de domínio." 56 Sempre que isso acontece, a realidade perde em complexidade e o artifício da navalha de Ockham torna-se instrumento de destruição. O cientificismo aprisiona a ciência, impedindo-a de cumprir a sua vocação na expansão do conhecimento, e impondo arbitrariamente limites à consideração da verdade. O impulso agressivo, hegemônico e absolutista do cientificismo, deturpa a amplitude e a profundidade da inclinação natural inerente ao desejo de conhecer. "O resultado desse assalto é um dogmatismo novo, quase religioso, conhecido como materialismo (ou fisicalismo), a crença de que o mundo físico, tal como o entende o método científico, é realmente tudo o que existe." ${ }^{57}$ A tentação cientificista opera uma obtusidade nefasta no horizonte do conhecimento, encurtando e limitando as suas perspectivas. "Muito embora a crítica Pós-Moderna haja denunciado a vontade manipuladora de controle que fomenta o reducionismo naturalista, ele continua a exercer enorme influência sociocultural. ${ }^{58} \mathrm{~A}$ investigação científica torna-se perniciosa e destrutiva quando reduzida à uma inclinação objetivante da realidade, sendo assim, desvinculada do puro desejo de conhecer. A fé enquanto confiança em uma verdade que se revela

\footnotetext{
54 CALDANA, Marcelo. Deus, o esquecido da ciência, p. 37.

SUSIN, Luiz Carlos. O estatuto epistemológico da teologia como ciência da fé e a sua responsabilidade pública no âmbito das ciências e da sociedade pluralista, p. 561. 
na liberdade e na gratuidade, por puro desejo de se dar a conhecer, pode ajudar a ciência a aceitar os seus limites e a superar a sua vontade de poder controlador.

\section{Conclusão}

A fé revelada enquanto expressão de uma confiança em um Deus que se rebaixa, irrompendo em um mundo submetido ao jugo das forças satânicas de poder, tem a sua importância capital diante da irrestrita vontade de dominação do cientificismo atual. A kênosis do rebaixamento de Deus liberta o desejo de conhecer das suas inclinações mais perversas, sendo condição de possibilidade para uma busca integral da verdade e do sentido da vida. ${ }^{59} \mathrm{O}$ Deus da promessa garante "a fidelidade ao desejo de conhecer como o critério fundamental da verdade." ${ }^{60}$ A fé revelada na sua integralidade, pode ser uma garantia para a promoção desse desejo, a fim de superar o pessimismo cósmico e o realismo trágico que resignam a pesquisa científica à obtusidade exclusiva do fisicalismo materialista. Além disso, a visão antecipatória da fé revelada rompe com a metafísica do passado, absolutizada pelo cientificismo, pois, a esperança bíblica, sabe conviver com um universo em curso de evolução, sem precisar para isso, recorrer a uma redução do mesmo, por medo das ambiguidades. ${ }^{61}$

Comumente, é a revelação que busca apoio na ciência, para ganhar credibilidade em um mundo secularizado. Contudo, Haught propõe que também o inverso possa ser válido, e até mesmo necessário. "A convicção profunda de que um novo futuro se abre diante de nós e de nosso universo inacabado, liberta não apenas o coração para uma vida de esperança, mas também a mente para uma vida de exploração irrestrita." ${ }^{\prime 2}$ A fé revelada auxilia a ciência a desenvolver as suas pesquisas para uma visão esperançosa da realidade. A ciência pode obter apoio da confiança suscitada pela revelação. O mistério do Deus revelado descortina a possibilidade de emergência futura de maior intensidade de ser, o que significa, proporcionalmente, maior grau de consciência. Teilhard de Chardin observou que na história cósmica, é possível perceber um

59 Cf. HAUGHT, John F. Cristianismo e ciência, p. 261.

60 HAUGHT, John F. Cristianismo e ciência, p. 265.

61 Cf. HAUGHT, John F. Cristianismo e ciência, p. 266.

62 HAUGHT, John F. Cristianismo e ciência, p. 266. 
crescente incremento de consciência evolutiva, que significa ampliação de ser, sendo esta a condição da existência do mundo. ${ }^{63}$

Pannenberg caracteriza a fé revelada como a confiança no advento do futuro, que permanece em aberto, repleto de possibilidades.$^{64} \mathrm{~A}$ fé revelada favorece assim, uma abertura para a esperança de renovação contínua do universo em evolução, ajudando a ciência a conviver com um universo inacabado e ambíguo, e fomentando o desejo de conviver em conjunção com uma esperança confiante que não reivindica para si a certeza absoluta, mas que tem disposição para esperar os dados por vir. A natureza enquanto tal tende para o futuro, e encontra a plenitude de seu florescimento na esperança religiosa da consumação escatológica. ${ }^{65}$ Conciliar a inteligência da fé com a racionalidade científica, significa deslocar a perspectiva do passado para o futuro, do pessimismo para a esperança, da compreensão limitada para a possibilidade de plena inteligibilidade e de libertação do desejo de conhecer.

\section{Referências}

ALLÈGRE, Claude. Deus face à ciência. Trad. Luís Serrano. Lisboa: Universidade de Aveiro, 1998.

ASSMANN, Hugo. Teologia e ciências: interdisciplinaridade e transdisciplinaridade. In: SUSIN, Luiz Carlos (Org.). Mysterium creationis: um olhar interdisciplinar sobre o Universo. São Paulo: Paulinas, 1999.

BARBOUR, Ian G. Quando a ciência encontra a religião. Trad. Paulo Salles. São Paulo: Cultrix, 2004.

BARTH, Wilmar Luiz. Religião, ciência e bioética. Porto Alegre: Edições Est, 2007.

BÍBLIA. Português. A Bíblia de Jerusalém. Nova edição rev. e ampl. São Paulo: Paulus, 2002.

BONÉ, Édouard. ¿Es Dios una hipótesis inútil? Evolución y bioética. Ciencia y fe. Trad. Miguel Montes. Maliaño: Sal Terrae, 2000.

\footnotetext{
63 Cf. TEILHARD DE CHARDIN, Pierre. How I Believe, p. 35.

64 Cf. PANNENBERG, Wolfhart. Faith and Reality, p. 58-59.

65 Cf. HAUGHT, John F. Cristianismo e ciência, p. 268.
} 
BRAKEMEIER, Gottfried. Ciência ou religião: quem vai conduzir a história? A urgência de um novo pacto. São Leopoldo: Sinodal, 2006.

CALDANA, Marcelo. Deus, o esquecido da ciência. Porto Alegre: Imprensa Livre, 2012.

CAPRA, Fritjof. O Tao da física: um paralelo entre a física moderna e o misticismo oriental. Trad. José Fernandes Dias. São Paulo: Cultrix, 1984.

COLLINS, Francis S. A linguagem de Deus: um cientista apresenta evidências de que Ele existe. Trad. Giorgio Cappelli. São Paulo: Gente, 2007.

DAWKINS, Richard. Deus, um delírio. Trad. Fernanda Ravagnani. São Paulo: Companhia das Letras, 2007.

DESCARTES, René. Meditações. In: Obra escolhida. Trad. Jacob Guinsburg; Bento Prado Jr. São Paulo: Difel, 1962.

FREIRE-MAIA, Newton. Criação e evolução: Deus, o acaso e a necessidade. Petrópolis: Vozes, 1986.

GEFFRÉ, Claude. Crer e interpretar: a virada hermenêutica da teologia. Trad. Lúcia M. Endlich Orth. Petrópolis: Vozes, 2004.

GESCHÉ, Adolphe. O ser humano. Trad. Euclides Martins Balancin. São Paulo: Paulinas, 2003.

HAMMES, Erico João. Teologia e evolução: uma hermenêutica da aliança. In: CRUZ, Eduardo R. da (Org.). Teologia e ciências naturais: teologia da criação, ciência e tecnologia em diálogo. São Paulo: Paulinas, 2011, p. 210-230.

HAUGHT, John F. Cristianismo e ciência: para uma teologia da natureza. Trad. Jonas Pereira dos Santos. São Paulo: Paulinas, 2009.

JESUS, Luciano Marques de. A questão de Deus na filosofia de Descartes. Porto Alegre: Edipucrs, 1997.

JOÃO PAULO II, Papa. Carta Encíclica Fides et Ratio: sobre as relações entre fé e razão. 3. ed. São Paulo: Paulinas, 1999.

KÜNG, Hans. O princípio de todas as coisas: ciências naturais e religião. Trad. Carlos Almeida Pereira. 3. ed. Petrópolis: Vozes, 2011.

McGRATH, Alister E. Fundamentos do diálogo entre ciência e religião. Trad. Jaci Maraschin. São Paulo: Loyola, 2005. 
MOLTMANN, Jürgen. Ciência e sabedoria: um diálogo entre ciência natural e teologia. Trad. Milton Camargo Mota. São Paulo: Loyola, 2007. MORANDINI, Simone. Teologia e fisica. Trad. Orlando Soares Moreira. São Paulo: Loyola, 2011.

NUMBERS, Ronald. Mitos e verdades em ciência e religião: uma perspectiva histórica. In: CRUZ, Eduardo R. da (Org.). Teologia e ciências naturais: teologia da criação, ciência e tecnologia em diálogo. São Paulo: Paulinas, 2011, p. 198-209.

OLIVEIRA, Manfredo Araújo de. Diálogos entre razão e fé. São Paulo: Paulinas, 2000.

PAIVA, Geraldo José de. A religião dos cientistas: uma leitura psicológica. São Paulo: Loyola, 2000.

PANNENBERG, Wolfhart. Faith and Reality. Trad. John Maxwell. Philadelphia: Westminster, 1977.

PASCAL, Blaise. Pensamentos. In: Os pensadores. Trad. Sérgio Milliet. 3. ed. São Paulo: Abril Cultural, 1984.

POLKINGHORNE, John. Ciencia y teología: una introducción. Trad. José Manuel Lozano-Gotor Perona. Maliaño: Sal Terrae, 2000.

RAHNER, Karl. Teologia e ciência. Trad. Hugo Assmann. São Paulo: Paulinas, 1971.

SCHELER, Max. La idea del hombre y la historia. Trad. Juan José Oliveira. Buenos Aires: Fausto, 1996.

SEIFERT, Josef. Pessoa, crença religiosa e verdade: análises filosóficas e reflexões sobre a filosofia da religião de Ludwig Wittgenstein. In: PICH, Roberto Hofmeister; ZILLES, Urbano (Orgs.). Filosofia, religião e ciência. Porto Alegre: Edições Est, 2009, p. 129-170.

STROEGER, William R. As leis da natureza: conhecimento humano e ação divina. Trad. Barbara Theoto Lambert. São Paulo: Paulinas, 2002.

SUSIN, Luiz Carlos. O estatuto epistemológico da teologia como ciência da fé e a sua responsabilidade pública no âmbito das ciências e da sociedade pluralista. Teocomunicação, Porto Alegre, v. 36, n. 153, p. 555-563, set. 2006.

TEILHARD DE CHARDIN, Pierre. How I Believe. Trad. René Hague. New York: Harper \& Row, 1969. 
TILLICH, Paul. Dynamics of Faith. New York: Harper Torchbooks, 1958. ZILLES, Urbano. A crítica da religião. Porto Alegre: Edições Est, 2009. . Crer e compreender. Porto Alegre: Edipucrs, 2004. . Desafios atuais para a teologia. São Paulo: Paulus, 2011. . O problema do conhecimento de Deus. 2. ed. Porto Alegre: Edipucrs, 1997. 2001. . Pierre Teilhard de Chardin: ciência e fé. Porto Alegre: Edipucrs, 